\title{
Effect on Efficiency of Lobe Performance in a Roots Blower
}

\author{
Pydiraju, M. Balakrishna
}

\begin{abstract}
A Roots blower is a mechanical device for moving air or other gases. As the flow process is highly complex in roots blower operation, it is necessary to analyses efficiency of lobes and develop the geometry of roots and casing to reduce the flow loss significantly. In the present thesis, the methodology to find near optimum combination of blower operating variables of performance.Roots blower are positive displacement device. In this study, roots blower is used to control the room conditions like temperature, moisture control, mist and transfer low volume intake into the system, increase the power efficiency of the engine. It is reliable, economical and having low maintenance cost.A roots blower performance depends on quality of air intake and geometry used. The quality of air major impact to the lobe arrangement and effect on temperature increase, reduced thickness of lobes and impact on performance of roots blower.
\end{abstract}

Key words: Lobes of Root Blower, Torque, Roots blower, Lobes.

\section{INTRODUCTION}

Roots blowers used to generate constant airflows that independent of discharge pressure conditions. Root blower applications limited to low and medium pressure and vacuum processes and can be used to provide small to large airflow rates.

Three lobes Roots Blower was new series Roots type blowers. A perfect gap to promote air performance, lower vibrations and noises results a significant improvement compared to traditional Roots Blower of two lobes Traditional Pressure Roots Blower lubricate bearings. Pressure Roots Blower is very convenient to maintain.

Compressors and Fans are essentially pumping for gases. They differ in construction from liquid handling machines, the principles of operations are similar. A roots blower performance depends on quality of air intake and geometry used. The quality of air major impact to the lobe arrangement and effect on temperature increase, reduced thickness of lobes and impact on performance of roots blower.

\section{CENTRIFUGAL BLOWERS \& FANS:}

This Range covers various types of Centrifugal and Axial Flow Fans, which have relatively high air displacement but low compression ratios. They are either of Centrifugal type, Axial flow types and Regenerative types.

Revised Manuscript Received on April 30, 2020.

* Correspondence Author

Ch. Pydiraju*, Department of Mechanical Engineering, Godavari Institute of Engineering and Technology (A), Rajahmundry, AP, India.

M. Balakrishna, Senior Assistant Professor, Department of Mechanical Engineering, Godavari Institute of Engineering and Technology, Rajahmundry (A), AP, India

(C) The Authors. Published by Blue Eyes Intelligence Engineering and Sciences Publication (BEIESP). This is an open access article under the CC BY-NC-ND license (http://creativecommons.org/licenses/by-nc-nd/4.0/)
As their internal clearances to be relatively high, the discharge pressures is limited to few inches of water only. Those types are generally used for applications requiring high volumes but low pressures such as in Air-conditioning, in furnaces, Low pressure Cooling, Dust or Fume extraction systems.

\section{POSITIVE DISPLACEMENT BLOWERS (ROOTS}

\section{BLOWERS):-}

Tri-lobe blowers are used presently in our locality industry. They have higher efficiency with moderate compression ratios, and they most efficient in the compression ratios of min and max. rate. we are used where constant flow rate at varying discharge pressures. Those are generally available for capacities $10 \mathrm{~m} 3 / \mathrm{hr}$ to $10000 \mathrm{~m} 3$ three-lobe rotor belongs to the category of positive displacement blower. They consist of a pair of involute shaped lobes/rotors rotating inside a oval shaped casing, closed outer ends by side plates. One end is a driving lobe which is connected to external power source. Those two rotors rotate one opposite to the second, by a set of timing gears.

\section{WATER AND EFFLUENT TREATMENT:}

Roots blowers are used to aeration to intake raw water, sewage and industrial organic waste. The aeration drives the digestion of the waste by microorganisms. Roots blowers are also used for grit tank cleaning, filter flushing, backwashing and the recovery of gases. Oil-free roots blowers are used for deep cell aeration.

Application

1. Wastewater treatment plants
2. Electroplating tanks
3. Activated sludge systems.
4. Drying systems.
And MANY MORE...

\section{LITERATURE REVIEW BASED ON INDUSRTIAL EXPOSURE}

This concept taken from based on industrial exposure Effect on efficiency of lobe performance in a root's blower

Aeration blowers receive a lot of attention from users' applications

variable process demands on the system is critical to optimizing the performance of the blowers.

In the present work, an experimental investigation is carried out to analyse quality of air and control of temperature in roots blower. 
Process flow chart of water treatment plant where we are executing blower application.

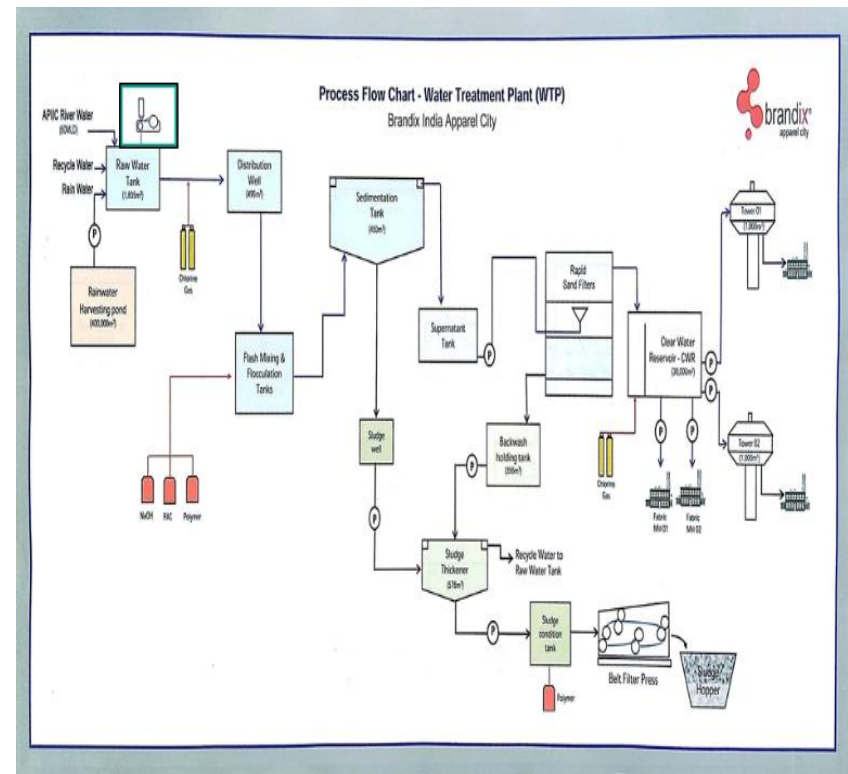

\section{BLOWER SPECIFICATIONS:}

\section{Working Principle:}

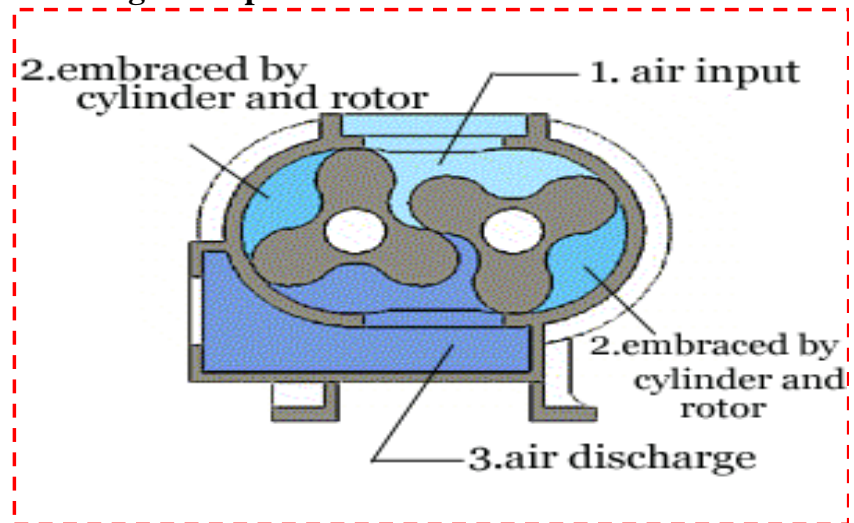

\section{The Processes are as Follows:}

Air input: Ambient air enter into the system Embraced by cylinder and rotor: Air compressed in between lobes and casing of roots blower

Air discharge: Low pressure compressed air Discharge from outlet.

Roots Blower compress air by two rotors' rotation. Three Lobe Blower also compress air by two rotors. Three Lobe Rotary Air Blowers under the category of Positive Displacement Blowers. They have of a pair of involutes profiled (angle $120^{\circ}$ ) and lobes/rotors rotating inside an oval shaped designed, closed at ends by side plates. One lobe is connected to external power source and its driving lobe and connected to driven lobe rotes in opposite direction with connectivity of equal gear ration. there is a 0.1 to $0.3 \mathrm{~mm}$ gap between two rotors, it does not need adding lubricating oil in between rotors. It can transport cleanly no oil moist air.

Due to these constructional features it has the following good characteristics.

- The flow is high dependent on the variation of speed
- The input Power is high dependent on the total pressure

- The Suction \& Discharge pressures are taken by the system conditions. The temperature generated of the discharge air is high
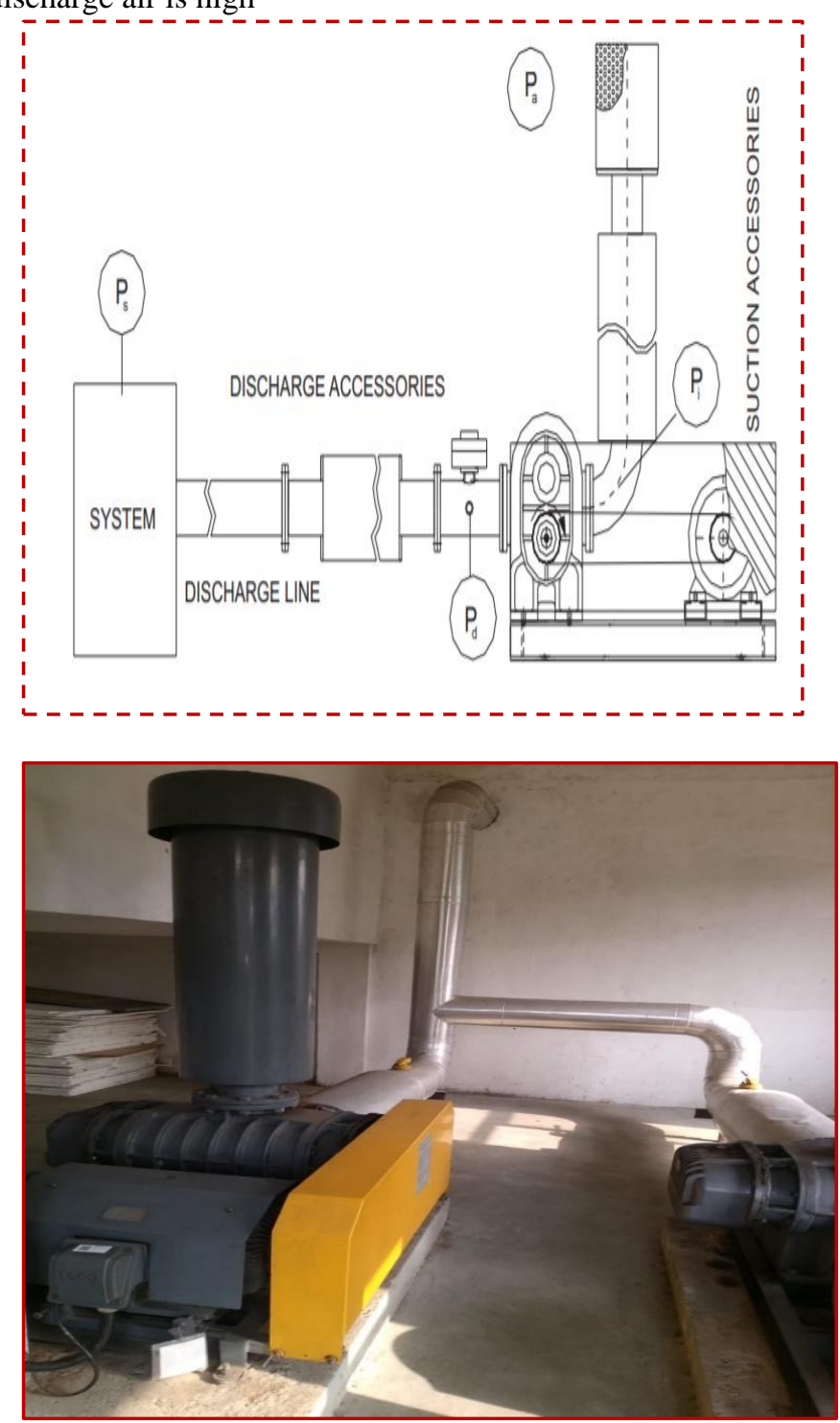

GENERALLY USED TERMS:

Ambient Pressure: Absolute pressure of the atmospheric air in environment.

Absolute Pressure: It is the algebraic sum of the atmospheric pressure and gauge pressure.

Gauge Pressure: Pressure measured above the atmospheric pressure

Static Pressure: Is the pressure of the gas measured in a manner that no effect due to velocity of air stream.

Rotary Air Blowers are widely used in applications demanding medium pressures and relatively high flow rates.

\section{Water treatment plants:}

- $\quad$ For aeration and backwashing of filter rock beds.

\section{Effluent Treatment Plants:}

- For diffused aeration for equalization tanks and agitation of effluent in OD tanks

Cement Plants: 
- For Aeration, Fluidisation, bending and Conveying of fluids

\section{Slurry Agitation:}

- For maintaining the Biological oxidation demand / Chemical oxidation demand

\section{Pneumatic Conveying:}

- Vacuum, Pressure and Combination Conveying of cereals, cement, husk, baggage, granules, powders and other similar material.

\section{Aquaculture:}

- For Maintaining the DO (dissolved oxygen) level.

\section{Biogas Boosting:}

- Transfer of Biogas from gas holding tank to boiler.

\section{EXPERIMENTAL METHOD}

1. Air filters for suction air

2. Pressure gauge

3. Breather for gear box

4. Thermal Image camera for temperature

5. Noise Level meter

6. Ultrasonic thickness gauge

7. Air velocity meter (Compact Anemometer) with thermal flow probe

8. Ambient Air quality machine (Environment department)

\section{Experimental Blower usage in Water treatment plant}

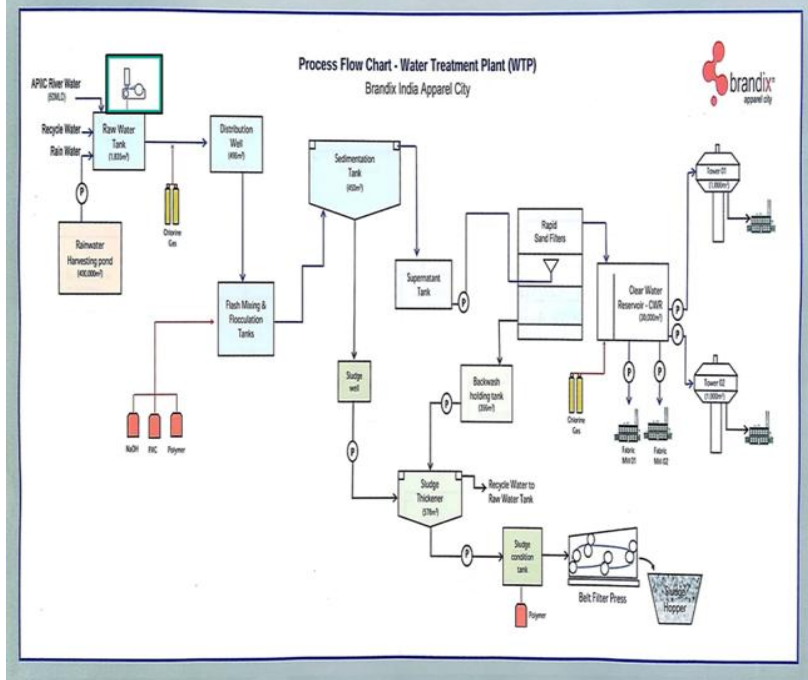

Blowers usage in raw water tanks and experimantal usage

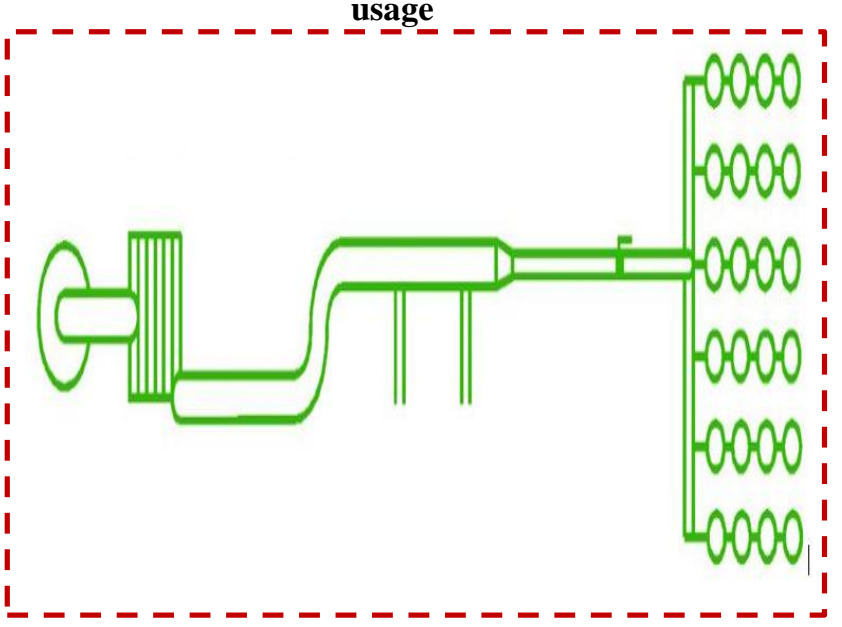

Blowers are using aeration in raw water tanks with complex treatment process or system. The process required constant air flow. System meets its requirement of discharge pressure and flow rate. Depends on air quality and process requirements with constant flow.

\section{The Experimental setup contains:}

\section{Air filters for suction air:}

We introduced to air quality filters for blower inlet or suction of blower. It's contained bio-migrate filter system having with 8-10-micron porous holes of filters system. High efficiency of filter cloth using in it. 10-micron high efficiency filter provides the protection from environment dust particle and required for high power usage vacuum truck blowers. The bio media filter cloth is pleated between two layers of epoxy coated wire mesh to prevent pleat collapse under high pressures as well as maintain consistent air flow. Its available for specific applications.

\section{Pressure gauge:}

Pressure gauge is one of the instruments for measuring the condition of a fluid (liquid or gas) under force or at rest condition, on a unit area, its denoted by newtons per square meters or centimetre. The reading on a pressure gauge, that is the difference between

two pressures known as the gauge pressure. We installed regular bourdon pressure gauge at inlet and outlet of pipeline of blower. Blower running with different revolutions (R/Min), different suction pressures noted. With effective of delivery pressure and noted efficiencies as well.

- Maximum Revolution: $1050 \mathrm{R} / \mathrm{min}$.

- Maximum pressure output at $1050 \mathrm{R} / \mathrm{min}: 600$ mmAq

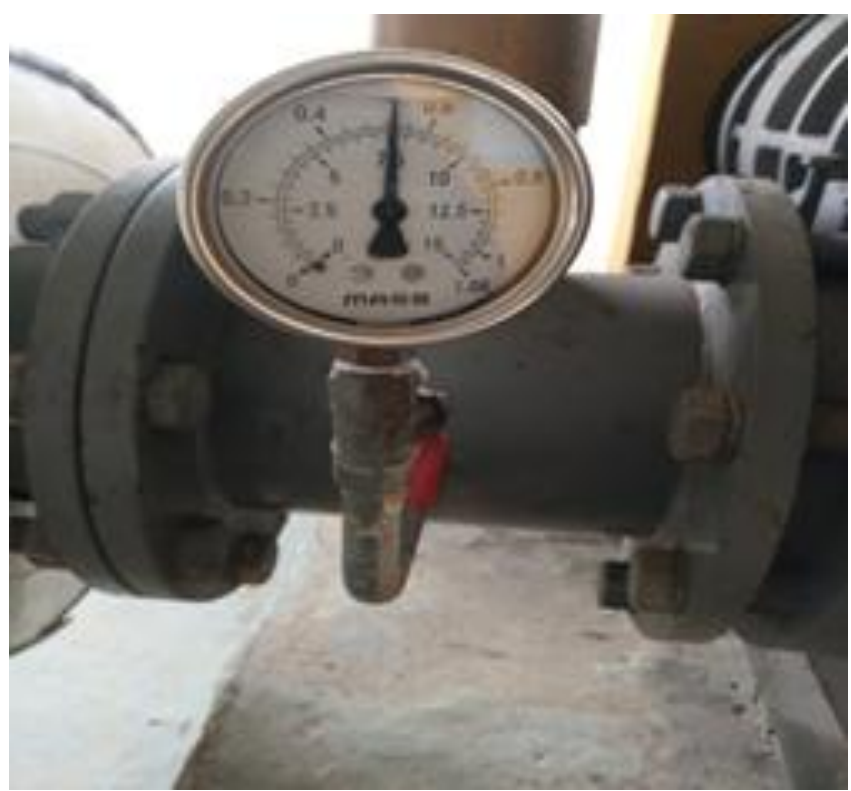

Total experiments of done by: 6 No's

- Suction pressure and delivery pressure at 600 revolution $(\mathrm{R} / \mathrm{min})$ of blower is 1.1 bar and 0.46 bar shown in pressure gauge with efficiency of $65.7 \%$ w.r.t design pressure. 
- Suction pressure and delivery pressure at 700 revolution $(\mathrm{R} / \mathrm{min})$ of blower is 1.11 bar and 0.49 bar shown in pressure gauge with efficiency of $70.0 \%$ w.r.t design pressure.

- Suction pressure and delivery pressure at 800 revolution $(\mathrm{R} / \mathrm{min})$ of blower is 1.12 bar and 0.52 bar shown in pressure gauge with efficiency of $74.3 \%$ w.r.t design pressure.

- Suction pressure and delivery pressure at 900 revolution $(\mathrm{R} / \mathrm{min})$ of blower is 1.11 bar and 0.55 bar shown in pressure gauge with efficiency of $78.6 \%$ w.r.t design pressure.

- Suction pressure and delivery pressure at 1000 revolution $(\mathrm{R} / \mathrm{min})$ of blower is 1.15 bar and 0.61 bar shown in pressure gauge with efficiency of $87.1 \%$ w.r.t design pressure.

- Suction pressure and delivery pressure at 1050 revolution $(\mathrm{R} / \mathrm{min})$ of blower is 1.14 bar and 0.62 bar shown in pressure gauge with efficiency of $88.6 \%$ w.r.t design pressure.

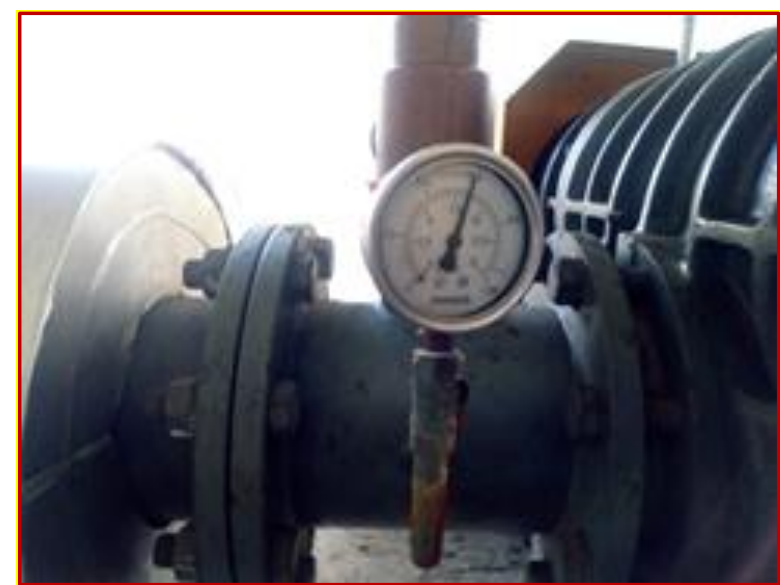

3.Breather for gear box / Lubrication cooling:

A breather is a important component of a gearbox. If a breather is not installed, pressure can develop and cause to oil leak by weak points by one or more seals from the gearbox. Oil loss from gear box is increased to heat generation in system. Internal components will be damaged and lead to more wear and tear of components and causes to gear box failure. A Breather can used for prevents pressure building up and allowed hot air into environment and takes cool air or fresh air into system. The quality of the air going into the gearbox can be completely depending on the environment. We are installed 40-micron filter breather for protection of heat generation in gearbox and cooler to system.

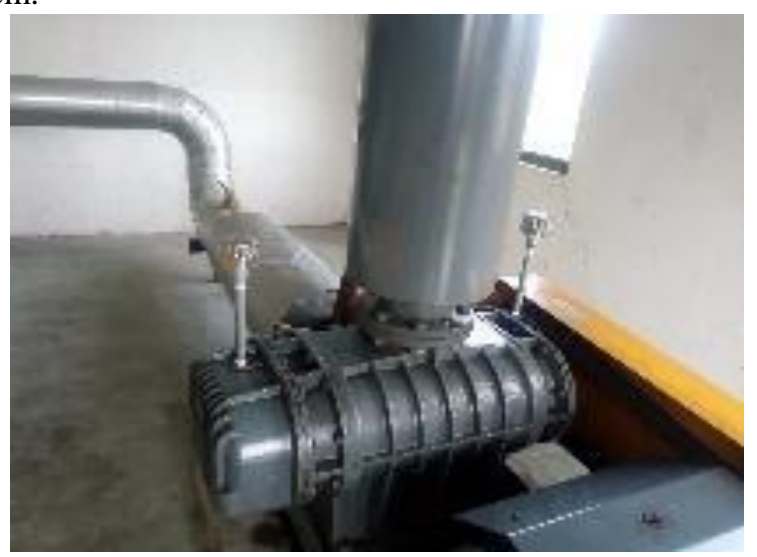

40 Micron Filter Breather: For those wanting a little more protection, the next breather that used in Inside/Moderate Outdoor Environments of 40-micron filter breather. This breather uses a ceramic filter inside to capture smaller particulate than the standard breather.

Types of Breathers used in industries:

1. 40 Micron filter Breather

2. Hydra lock desiccant Breather

3. Totally enclosed Chamber Breather.

\section{Thermal Image camera for temperature measurement:}

Thermal imaging cameras are devices, translate thermal heat energy into visible light in order to analyse a object. The image produced is known as a thermogram and is analysed through a process called thermography. Thermal imaging cameras are devices that process the captured image and display it on a screen.

\section{What Do with Thermal Imaging Cameras?}

Visible light is everyday watch around the environment. It's one of the electromagnetic spectrums rea in the electromagnetic spectrum and infrared radiation (IR) represents a larger percentage. We need specialization components for measuring higher temperatures.

All objects absorb temperature, reflect and sometimes transmit energy at different levels. It's this energy that can be detected by infrared equipment and displayed as images.

Thermal Imaging Camera Applications and Uses

- $\quad$ migrated into other fields

- Firefighters use them to see through smoke

- localize hotspots of fires.

- to manage surveillance activities,

- $\quad$ Power line maintenance

- to improve the efficiencies of cooling or heating

- human beings and other warm-blooded animals

- Thermal Imaging Camera Features

Thermal Imaging Camera Limitations

- Thermal imaging cameras cannot see through glass.

- They cannot see through walls.

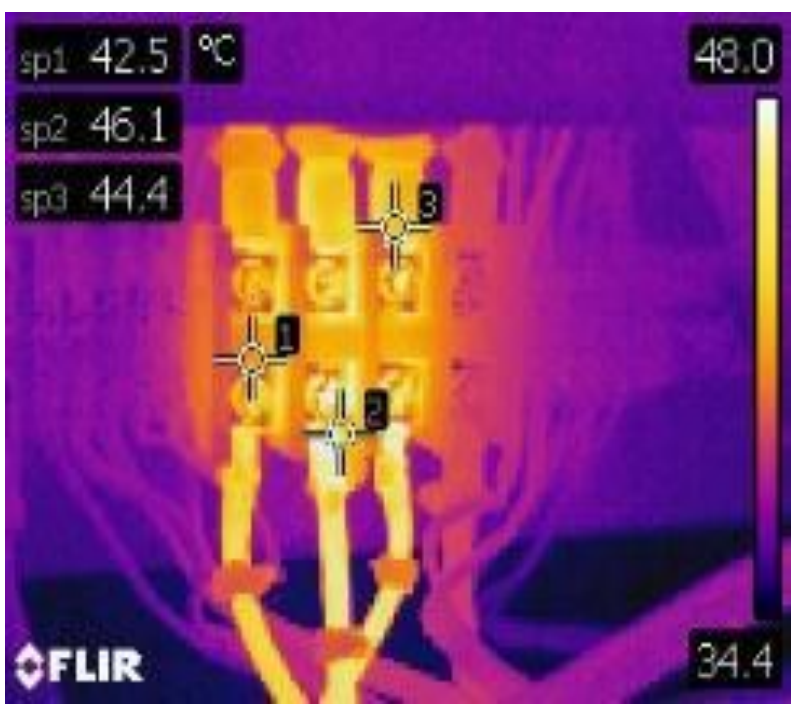

* Maximum temperature detected: $73^{0} \mathrm{C}$ (Before Breather Used)

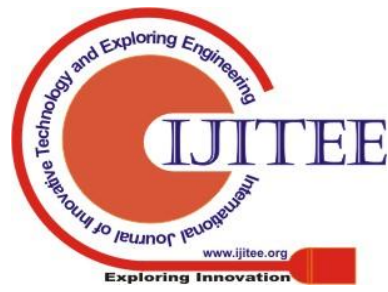


* Minimum temperature detected: $42.5^{\circ} \mathrm{C}$ (After Breather Used)

\section{Total experiments of done by: 6 No's}

Constant higher revolutions at 1050 revolution $(\mathrm{R} / \mathrm{min})$ of blower. Temperature varies in between $\min$ and $\max$ temperatures detected through Thermal image camera with effectiveness of $88.6 \%$.

\section{Noise Level meter}

A sound level meter is a measuring instrument used to assess noise or sound levels. Other names of sound or noise level sound pressure level (SPL) meter, decibel $(\mathrm{dB})$ meter, noise meter or noise dosimeter. A sound level meter uses a microphone to capture sound. The sound level meter and acoustic measurement values are shown on the display of the sound level meter. The unit of acoustic measurement for sound is the decibel $(\mathrm{dB})$; By using with a portable sound level meter installed for continuous monitoring of sound levels at a work or job it of blowers.

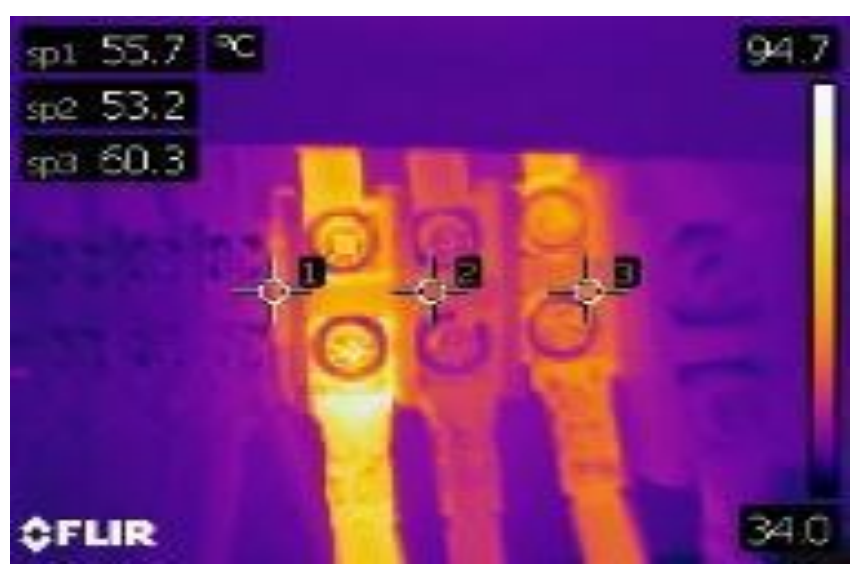

\section{Ultrasonic thickness gauge}

An ultrasonic thickness gauge is a measuring instrument for the non-destructive investigation of a material's thickness. Its capturing values by using ultrasonic waves. An ultrasonic thickness gauge for thickness measurement, is regularly used in all areas of industrial measurements. Its measured values of single side of measuring plate of equipment or material. its widely being used for wall thickness for Glass, Wood, plastics and serves as major testing equipment in corrosion industry.

\section{Advantages}

* Non-destructive technique

* Not require access to both sides of the material

* Coatings, linings

* Good accuracy up to $0.1 \mathrm{~mm}$ and less

* Can be easily deployed, does not require laboratory conditions

* Its Cheap equipment

* EMAT

* No need to remove the coating of the metal.

\section{Disadvantages}

* Requires calibration for each and every different material

* Requires good contact or connection with contact point of material

* Cannot be measured over rust materials
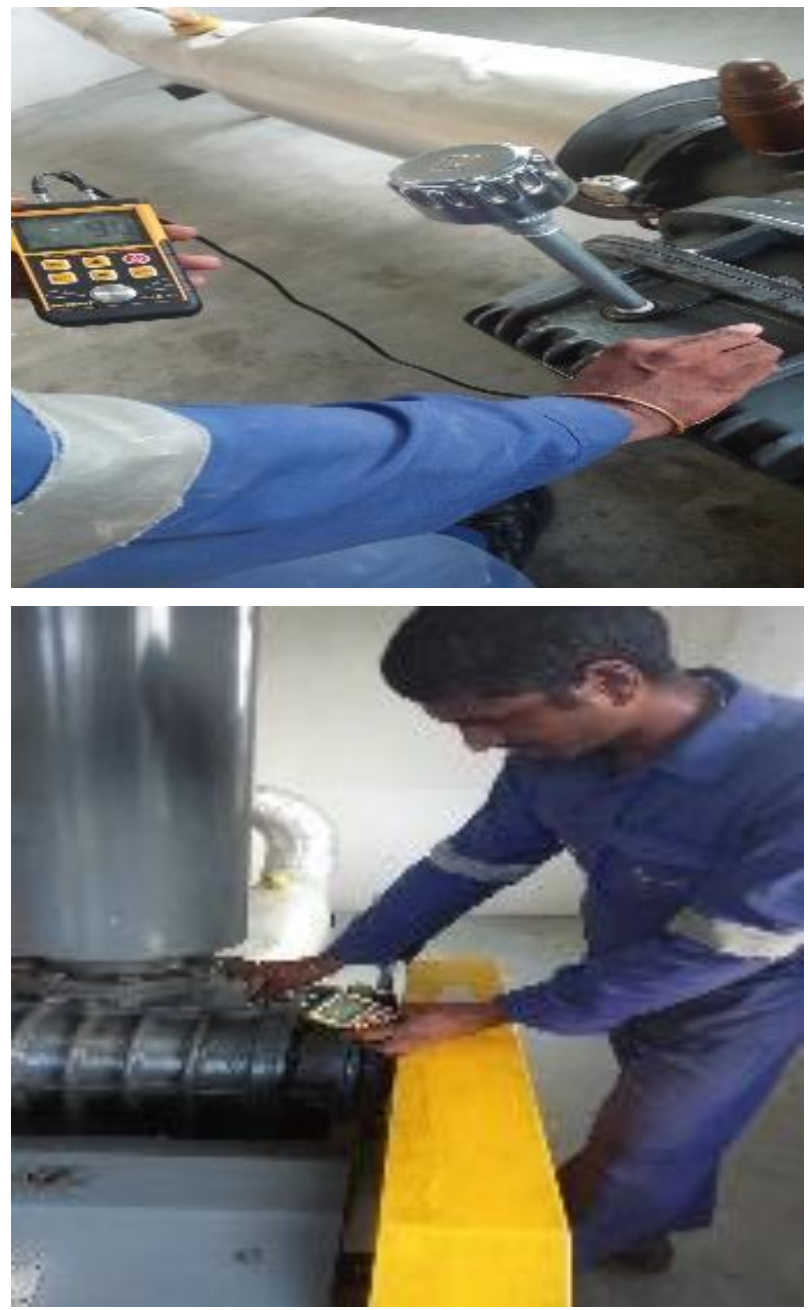

7.Air velocity meter or Compact Anemometer with thermal flow probe instrument:

Air velocity meter used for measuring air flow of inlet system of blower and its measured to Air velocity. For measuring of air quality and air measuring using of The Testo 425 air velocity instrument. Its automatically measures air velocity and calculates volumetric air flow.

\section{It contains:}

- Air flow measurement and volumetric flow calculation

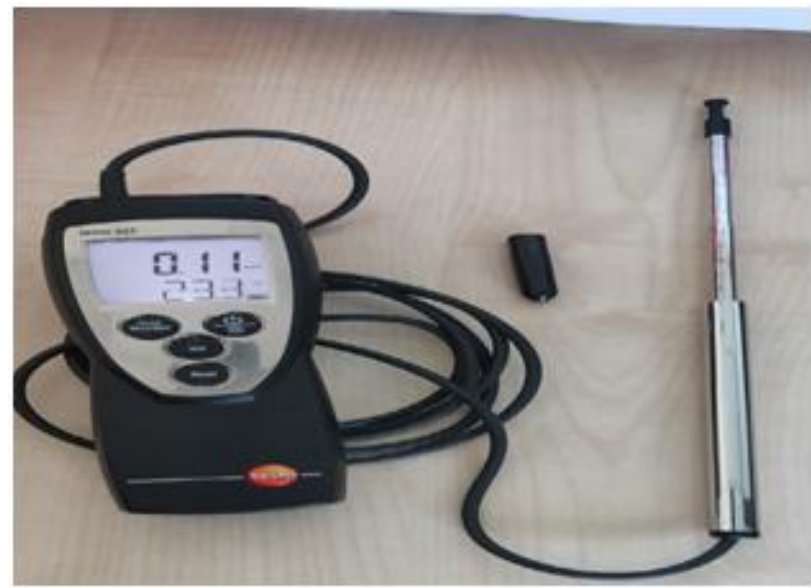

- Its attached extension telescopic probe

- Single and multi-point averaging readings

- Its Hold function,

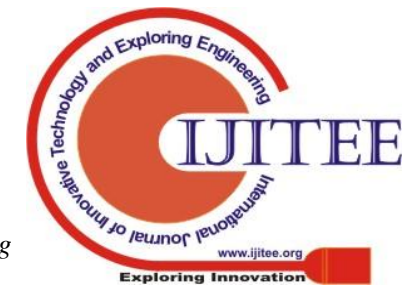


- It contains Display of min/max value,

- Its function with Auto-off function

Using Testo 425 air velocity meter for flow measurement:

The Testo 425 air velocity meter records the flow speed and calculates the volumetric flow.

$\circ$ Measuring range of 0 to $+20 \mathrm{~m} / \mathrm{s}$,

- Air velocity meter is suited to low air flow velocity.

O The air velocity meter features a telescopic flow probe.

- Telescope can be extended to a length of up to 800 $\mathrm{mm}$ and has a probe head diameter of $6 \mathrm{~mm}$.

$\circ \quad$ volumetric flow during the flow measurement.

\section{RESULTS}

A root blower used in water treatment plant and effluent treatment plants for aeration purpose. After usage of 10 years blower lobes and meeting junctions like casing are wear and tear. Its causes reduction of efficiency in roots blower.

After installation of air filter, breather, testing from thermal image camera for temperature monitoring. Breather used for reducing the temperature in gear box and lubrication temperature.

All results are shown in tables and graphs.

- As per design, roots blower should get maximum efficiency of air transfer is $18.4 \mathrm{~m} 3 / \mathrm{min}$

- Installation of all requirements and we are getting $16.78 \mathrm{~m} 3 / \mathrm{min}$ of air transfer.

- During this process observe Temperature raise maximum at terminal connectors is $73.3^{0} \mathrm{C}$ After installation of Breather and insulation provided to pipeline up to end process, Temperature comes down to $53.7^{0} \mathrm{C}$

- Maximum temperature difference is $19.7^{0} \mathrm{C}$ (Huge difference from the system)

Get the maximum effective pressure 0.62 out of 0.7 design pressure and efficiency is $92 \%$ after installation of Breather, Bio Air filters, insulation apply to pipeline.

\begin{tabular}{|c|c|c|c|c|}
\hline S.No & $\begin{array}{c}\text { Revolutions } \\
\text { (R/min) }\end{array}$ & $\begin{array}{c}\text { Suction } \\
\text { Pressure } \\
(\text { barr })\end{array}$ & $\begin{array}{c}\text { Deliver } \\
\text { pressure } \\
(\text { bar) }\end{array}$ & $\begin{array}{c}\text { Efficiency } \\
(\%)\end{array}$ \\
\hline 1 & 600 & 1.1 & 0.46 & 65.7 \\
\hline 2 & 700 & 1.11 & 0.49 & 70.0 \\
\hline 3 & 800 & 1.12 & 0.52 & 74.3 \\
\hline 4 & 900 & 1.11 & 0.55 & 78.6 \\
\hline 5 & 1000 & 1.15 & 0.61 & 87.1 \\
\hline 6 & 1050 & 1.14 & 0.62 & 88.6 \\
\hline
\end{tabular}

\section{Delivery pressure graph}

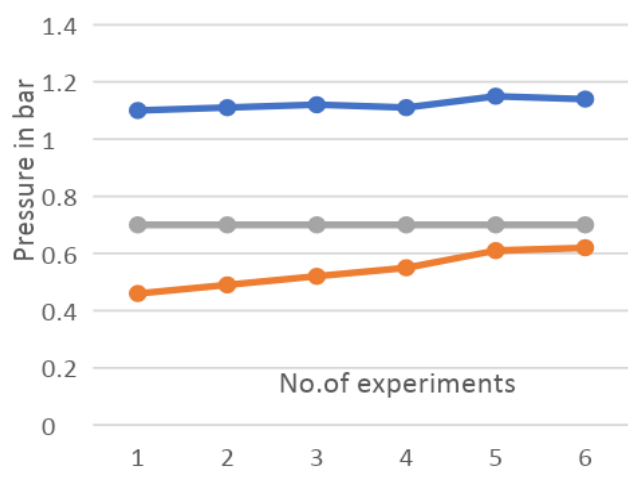

Deliver pressure (bar)

Design pressure (bar)

\begin{tabular}{|c|c|c|c|c|c|}
\hline S.No & $\begin{array}{c}\text { Revolutions } \\
\text { (R/min) }\end{array}$ & $\begin{array}{c}\text { Motor } \\
\text { terminal box } \\
\text { Temperature } \\
\left({ }^{\circ} \mathrm{C}\right) \text { - } \\
\text { Before }\end{array}$ & $\begin{array}{c}\text { Motor } \\
\text { terminal box } \\
\text { Temperature } \\
\text { ("C) - After }\end{array}$ & Difference & $\begin{array}{c}\text { Efficiency } \\
(\%)\end{array}$ \\
\hline 1 & 1050 & 55.7 & 42.5 & 13.2 & 58.6 \\
\hline 2 & 1050 & 53.2 & 46.1 & 7.1 & 67.1 \\
\hline 3 & 1050 & 60.3 & 44.4 & 15.9 & 72.9 \\
\hline 4 & 1050 & 67.1 & 55.4 & 11.7 & 77.1 \\
\hline 5 & 1050 & 73.3 & 53.7 & 19.6 & 86.4 \\
\hline 6 & 1050 & 62 & 57.8 & 4.2 & 88.6 \\
\hline
\end{tabular}

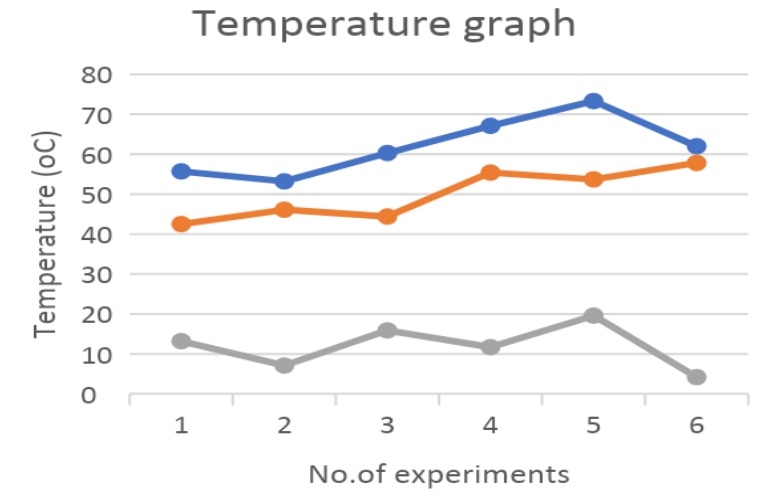

Motor terminal box Temperature (oC) - Before Motor terminal box Temperature (oC) - After Difference 


\begin{tabular}{|c|c|c|c|c|c|c|}
\hline SNOO & $\begin{array}{l}\text { Revolutions } \\
\text { (R/min })\end{array}$ & $\begin{array}{l}\text { Oischarge } \\
\text { Velocity/(m/s) }\end{array}$ & 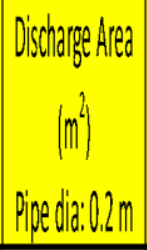 & $\begin{array}{l}\text { Discharge } \\
\text { quantity } \\
\left(\mathrm{m}^{3} / \mathrm{min}^{2}\right. \\
\end{array}$ & Aird density & $\begin{array}{l}\text { Massflow } \\
\text { rate } \\
\text { |kgemin }\end{array}$ \\
\hline 1 & 600 & 5,52 & 0.0314 & 10,39 & 1.16 & 121 \\
\hline 2 & 700 & 631 & 0.3114 & 11.89 & 1.11 & 13.2 \\
\hline 3 & 800 & 7.16 & 0.0314 & $13: 49$ & 1.09 & 14.7 \\
\hline 4 & 900 & 7.80 & 0.1314 & 14.69 & $1 . N_{4}$ & 15.3 \\
\hline 5 & 1000 & 8.16 & 0.314 & $15: 19$ & 1.03 & 15.6 \\
\hline 6 & 1050 & 8.91 & 0.314 & 1678 & 1.01 & 17.0 \\
\hline
\end{tabular}

\begin{tabular}{|c|c|c|c|c|c|c|}
\hline $\begin{array}{l}\text { S. } \\
\text { N } \\
0\end{array}$ & $\begin{array}{l}\text { Revolut } \\
\text { ions } \\
(\mathrm{R} / \mathrm{min})\end{array}$ & $\begin{array}{c}\text { Disc } \\
\text { harg } \\
\text { e } \\
\text { Vel } \\
\text { ocit } \\
y \\
(\mathrm{~m} / \mathrm{s} \\
)\end{array}$ & $\begin{array}{c}\text { Dischar } \\
\text { ge Area } \\
\left(\mathrm{m}^{2}\right) \\
\text { Pipe dia: } \\
0.2 \mathrm{~m}\end{array}$ & $\begin{array}{c}\text { Disch } \\
\text { arge } \\
\text { quanti } \\
\text { ty } \\
\left(\mathrm{m}^{3} / \mathrm{m}\right. \\
\text { in })\end{array}$ & $\begin{array}{c}\text { Desig } \\
\text { n } \\
\text { capac } \\
\text { ity } \\
(\mathrm{m} 3 / \\
\mathrm{min})\end{array}$ & $\begin{array}{c}\text { Efficie } \\
\text { ncy } \\
(\%)\end{array}$ \\
\hline 1 & 600 & 5.52 & 0.0314 & 10.39 & 18.4 & 56.5 \\
\hline 2 & 700 & 6.31 & 0.0314 & 11.89 & 18.4 & 64.6 \\
\hline 3 & 800 & 7.16 & 0.0314 & 13.49 & 18.4 & 73.3 \\
\hline 4 & 900 & 7.80 & 0.0314 & 14.69 & 18.4 & 79.8 \\
\hline 5 & 1000 & 8.06 & 0.0314 & 15.19 & 18.4 & 82.5 \\
\hline 6 & 1050 & 8.91 & 0.0314 & 16.78 & 18.4 & 91.2 \\
\hline
\end{tabular}

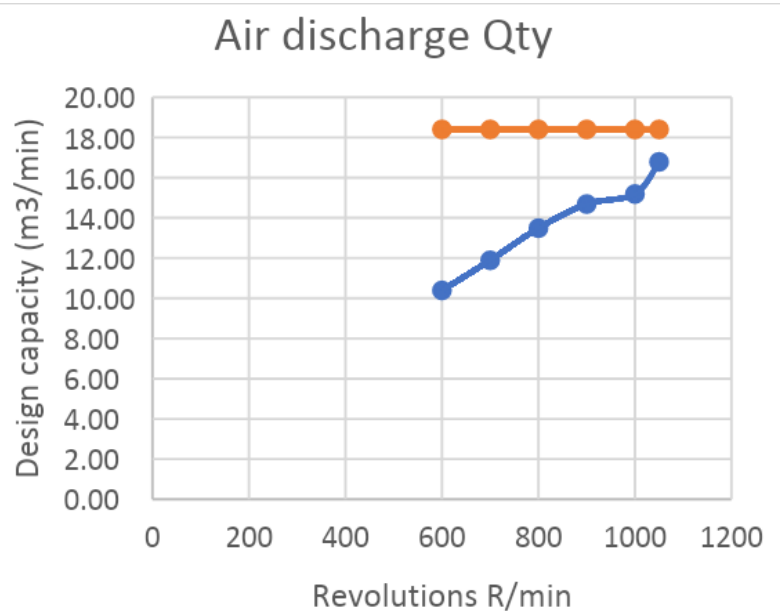

Dischrge quantity $(\mathrm{m} 3 / \mathrm{min})$

Design capacity $(\mathrm{m} 3 / \mathrm{min})$

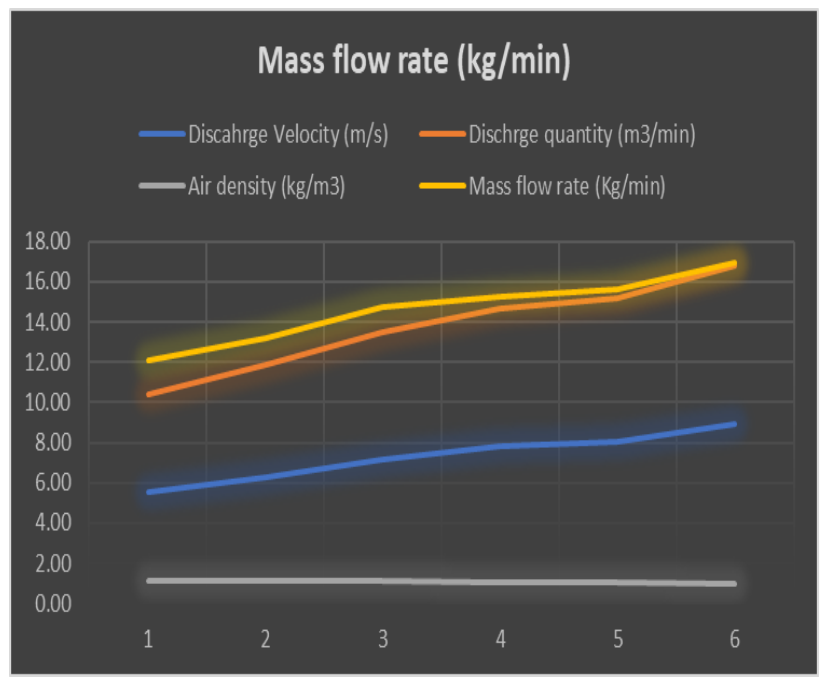

V. CONCLUSION

After installation of air filter, breather, testing from thermal image camera for temperature monitoring. Breather used for reduced the temperature in gear box and lubrication temperature. As per design, roots blower should get maximum efficiency of air transmission is 18.4 $\mathrm{m} 3 /$ minInstallation of all requirements and we are getting $16.78 \mathrm{~m} 3 / \mathrm{min}$ of air transmission.During this process observe Temperature raise maximum at terminal connectors is $73.3^{\circ} \mathrm{C}$ After installation of Breather and insulation provided to pipeline up to end process, Temperature comes down to $53.7^{\circ} \mathrm{CMaximum}$ temperature difference is $19.7^{\circ} \mathrm{C}$ (Huge difference from the system)Maximum Mass stream rate noted as $17 \mathrm{Kg} / \mathrm{min}$ Get the maximum effective pressure 0.62 out of 0.7 design pressure and efficiency is $92 \%$ after installation of Breather, Bio Air filters, insulation apply to pipeline.

\section{REFERENCES}

1. International Journal of Engineering Research \& Technology

2. Ashish, M,Joshi, David I. Blekhman, James D. Felske, John A. Lordi, C.Mollendrof, (2006), Clearance Analysis and Leakage Flow CFD Model of a Two-Lobe MultiRecompression Heater. International Journal of Rotating Machinery Volume 2006, Article ID 79084, Pages 1-10 DOI 10.1155/IJRM/2006/79084.

3. Cheng, X., Lia R., 2012, Parameter equation study for screw centrifugal pump, Procedia Engineering 31, 914 - 921. Chiu, H.C. 1994, The mathematical model and computer aided manufacturing of Roots blower rotor profile, Journal of Technology 9 (1), 13-19.

4. Chyang, C.S., Lin Y.C., 2002, Influence of the nature of the Roots blower on pressure fluctuations in a fluidized bed, Powder Technology 127, 19-31.

5. Fang, H.S., 1992, Rotor profile for a roots vacuum pump, U.S. Patent $5,152,684$.

6. Dong, D., Meng, X., Liang, L., 2011, Decoupling control of doublelevel dynamic vacuum system based on neural networks and prediction principle, Vacuum 86, 39-43.

7. Ferreira, C.A., Infants, Z. C., Zaytsev, D., 2005.Twin screw oil-free wet compressor for compression-absorption cycle, International Journal of Refrigeration 29, 556-565.

8. Fleming, J.S., Tang, Y., You, C.X., 1995. Shutdown process simulation of a refrigeration plant having a twin screw compressor, International Journal of Refrigeration 19, 422- 428.

9. Design and capacity data taken from manufacturer of LONGTECH Machinery industry Co Ltd, TAIWAN. 
10. Technical data taken from Wikipedia and textbooks.

11. Images taken from industrial exposure and working.

12. https://beeindia.gov.in/sites/default/files/3Ch5.pdf

13. https://www.smcin.com/product-category/air-suction-filters

14. https://www.britannica.com/technology/pressure-gauge

15. https://www.baldor.com/mvc/DownloadCenter/Files/WP0236

16. https://en.wikipedia.org/wiki/Ultrasonic_thickness_measuremet

17. http://www.horiba.com/ru/process-environmental/products/systemengineering/air-quality-monitoring-system/

18. https://www.blowervacuumbestpractices.com/technology/aerationblowers/aeration-blower-control-efficiency

19. http://www.rootsblower.com.tw/en/features-103/Technical.html

20. http://www.rootsblower.com.tw/en/product-286850/Fixed-Bio-filmMedium.html

21. http://www.everestblowers.com/wpcontent/uploads/2017/05/understanding-lobe-blowers-rootsblower.pdf

22. https://www.researchgate.net/search/authors?q=roots\%2Bblowers

23. https://en.wikipedia.org/wiki/Roots-type_supercharger

24. https://www.baldor.com/mvc/DownloadCenter/Files/WP0236

25. https://livhaven.com/wp-content/uploads/2016/01/hbv.pdf

\section{AUTHORS PROFILE}

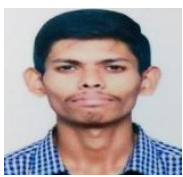

CH. Pydiraju, PG Scholar of $\mathrm{M}$. Tech in THERMAL ENGINEERING in the Department of Mechanical Engineering, Godavari Institute of Engineering and Technology (A), Rajahmundry, AP, India.

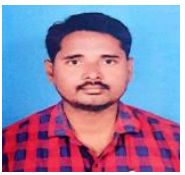

M. Balakrishna working as Senior Assistant Professor in the Department of Mechanical Engineering, Godavari Institute of Engineering and Technology, Rajahmundry (A), AP, India. 